Original Article

\title{
Relations of morale and physical function to advanced activities of daily living in health promotion class participants
}

\author{
Masahide Yajima, RPT, MS ${ }^{1,2)^{*}}$, Yasuyoshi Asakawa, RPT, $\mathrm{PhD}^{3)}$, \\ Haruyasu Yamaguchi, MD, $\mathrm{PhD}^{2)}$ \\ 1) Department of Rehabilitation, Faculty of Health and Medical Care, Nihon Institute of Medical \\ Science: 1276 Shimogawara, Moroyama-machi, Iruma-gun, Saitama 350-0435, Japan \\ 2) Faculty of Medicine, School of Health Sciences, Gunma University, Japan \\ 3) Tokyo Metropolitan University, Japan
}

\begin{abstract}
Purpose] The aim of this study was to clarify the relations of morale and physical function to the presence/absence of advanced activities of daily living. [Subjects] The subjects were 86 elderly community residents participating in health promotion classes. [Methods] A questionnaire survey on age, gender, presence/absence of advanced activities of daily living, and Philadelphia Geriatric Center Morale Scale score was conducted, in addition to assessment of fitness, consisting of measurement of height, body weight, grip and knee extensor muscle strength, functional reach, one-leg standing time, and Timed Up and Go test. Furthermore, multiple logistic regression analysis was performed with the presence/absence of advanced activities of daily living as a dependent variable. [Results] Grip strength and Timed Up and Go time were identified as variables influencing the presence/absence of advanced activities of daily living. [Conclusion] Physical function represented by grip strength and Timed Up and Go time was higher among subjects performing advanced activities of daily living.

Key words: Advanced activities of daily living, Physical function, Philadelphia Geriatric Center Morale Scale
\end{abstract}

(This article was submitted Oct. 8, 2015, and was accepted Nov. 6, 2015)

\section{INTRODUCTION}

Advanced activities of daily living (AADL) are based on intentional conducts involving physical, mental, and social functioning that allow the individual to develop multiple social roles and maintain good mental health and quality of life $\mathrm{e}^{1,2)}$. Assessment of AADL may be a sensitive measure of earlier functional decline $e^{1,3,4)}$. AADL are classified as higher levels of activity than basic or instrumental ADL and include enjoying social events such as travelling, parties, sports such as golf and tennis, music concerts, and movies.

AADL are likely to be an important factor for well-being. Grossarth-Maticek et al. ${ }^{5}$ conducted a questionnaire survey using the Pleasure and Well-being Inventory (PWI), involving community residents aged 45 to 65 without serious chronic diseases, and reported that the survival rate at 21 years later was higher for those showing higher scores, suggesting the possibility of AADL influencing survival rates. On the other hand, in a study conducted by Michael et al. ${ }^{6}$ to examine mental health, vitality, and physical function in elderly community residents, social participation, such as community-based and volunteer activities, was shown to be effective in preventing physical activity levels from decreasing, confirming the usefulness of AADL in reducing the risk of functional disorders.

Encouraging the elderly to perform AADL is an important challenge in achieving well-being. However, the factors related to the presence/absence of such activities have remained unclear. This study aimed to clarify the contents of elderly commu-

\footnotetext{
*Corresponding author. Masahide Yajima (E-mail: m-yajima@nims.ac.jp)

(C)2016 The Society of Physical Therapy Science. Published by IPEC Inc.

This is an open-access article distributed under the terms of the Creative Commons Attribution Non-Commercial No Derivatives (by-nc-nd) License $<$ http://creativecommons.org/licenses/by-nc-nd/4.0/>.
} 
nity residents' AADL, as well as the relations of morale and physical function, such as muscle strength and walking ability, with the presence/absence of AADL.

\section{SUBJECTS AND METHODS}

\section{Subjects}

Eighty-six elderly community residents (mean age $=76.7$ years, age range: $65-88$ years) who were participating in health promotion classes (exercise training to mainly prevent falls) at 14 venues located in Yoshiokamachi, Gunma Prefecture, Japan, were included in the study. These subjects met the following inclusion criteria: ability to independently access a venue and appropriate understanding and implementation of the study procedures.

This study was conducted with the approval of the Gunma University Epidemiologic Research Ethics Committee (approval number: 23-12). In addition, on the day of the study, the participants were provided with oral and written explanations of the study and its procedures individually, and those who consented were included in the study.

\section{Methods}

A questionnaire survey and fitness assessment were conducted, the former of which examined age, gender, presence/ absence and contents of AADL, and the Philadelphia Geriatric Center Morale Scale (PGC Morale Scale) score. The presence/ absence of AADL was determined based on the participants' answers to related questions (Do you have any hobbies or activities that you enjoy at present?), adopting a 2-point scale: Yes/No. The PGC Morale Scale ${ }^{7)}$ consists of 17 items reflecting 3 factors: agitation, attitude toward own aging, and lonely dissatisfaction. For each item, positive answer choices and others were graded as 1 and 0 , respectively. The total score, calculated by simply totaling the score for each item, ranged from 0 to 17 .

The fitness assessment consisted of measurement of height, body weight, and physical function represented by grip and knee extensor muscle strength, functional reach (FR), one-leg standing (OLS) time, and Timed Up and Go (TUG) test. Each item was measured twice. For grip and knee extensor muscle strength, FR, and OLS time, the maximum values were adopted; the OLS time was limited to a maximum of 120 seconds. In contrast, for the TUG time, the minimum value was adopted. The values representing grip and knee extensor muscle strengths were adjusted for body weight (calculating the ratios of grip and knee extensor muscle strengths to body weight) and used for analysis. The details of each measurement are described below.

Grip strength and FR were measured using the dominant hand, while knee extensor muscle strength and OLS time were measured using the dominant leg. The dominant hand and leg were defined as the hand used to hold chopsticks when eating and the leg used to kick a ball, respectively. On measurement of knee extensor muscle strength, the maximum isometric knee extension, executed while sitting in a chair with the knee flexed to 90 degrees, was measured in the frontal part of the ankle at the superior border of the medial malleolus, using a handheld myometer with an attached belt ( $\mu$ TAS MF-1, ANIMA Corp.) and adopting the make test method $^{8)}$. For the FR test, the reach distance was measured when stretching the hands in the anterior horizontal direction in a standing position with the shoulders flexed to 90 degrees, using the method of Duncan et al. $\left.{ }^{9}\right)$ and a meter (CK-101, SAKAI Medical Co., Ltd.). The TUG test was conducted based on the method of Podsiadlo et al. ${ }^{10)}$; the participants initially sat in an armless chair at a height of $40 \mathrm{~cm}$ (an attachment for the CK-101, SAKAI Medical Co., Ltd.), stood up from the chair to walk at maximum velocity toward a pole (CK-103, SAKAI Medical Co., Ltd.) placed $3 \mathrm{~m}$ in front of them, walked around it, and then returned to sit in the chair again to measure the time needed to implement the entire task. Regarding the walking velocity, the participants were instructed to walk as fast as possible.

For analysis, the basic attributes and PGC Morale Scale scores of the subjects with and without AADL were used. To compare their physical function, the $\chi^{2}$ test, Student's t-test, and Mann-Whitney U test were used. Furthermore, multiple logistic regression analysis was performed with items showing significant values in univariate analysis and the presence/ absence of AADL as independent and dependent variables, respectively. Variables were selected using the likelihood ratio test and step-up method. Subsequently, age and gender were forcibly entered as confounding variables. Regarding multicollinearity, the correlation between the measurement items was examined by calculating Spearman's rank correlation coefficient to confirm the absence of combined variables showing strong correlations. Additionally, for the items identified as influencing the presence/absence of AADL based on the results of multiple logistic regression analysis, the receiver operating characteristic (ROC) curve was used to calculate the area under the curve (AUC) and the cutoff. For statistical analysis, IBM SPSS Statistics 21 for Windows was used. $\mathrm{P}<0.05$ was considered statistically significant.

\section{RESULTS}

Among the 86 participants, $26(30.2 \%)$ and $60(69.8 \%)$ were males and females, respectively, and $74(86.0 \%)$ and 12 $(14.0 \%)$ were classified as those with and without AADL, respectively. Gender showed no significant difference $\left(\chi^{2}=1.22\right.$, $\mathrm{df}=1, \mathrm{p}=0.27$ ). The most frequent types of AADL were ground golf (the sport of putting a ball into a post like kago, a type of sport invented in Japan for elderly people), engaged in by 19 subjects (25.7\%); karaoke (the act of singing with recorded accompaniment), engaged in by 10 subjects (13.5\%); travelling, engaged in by 9 subjects $(12.2 \%)$; farm work, engaged in by 5 subjects $(6.8 \%)$; and dancing (a rhythmic body action performed for a limited time in limited space to promote the transmis- 
sion of emotion and resolve), engaged in by 5 subjects (6.8\%). As shown in Table 1, significant differences were observed in basic attributes, PGC Morale Scale scores, and physical function between subjects with and without AADL; more concretely, the score for the PGC Morale Scale attitude toward own aging sub-scale, ratio of grip strength to body weight, FR, and OLS and TUG times were more favorable among subjects with AADL.

In our univariate analysis, the PGC Morale Scale attitude toward own aging subscale, ratio of grip strength to body weight, FR, and OLS and TUG times showed significant values. Regarding multicollinearity, the absence of combined variables showing strong correlations was confirmed by calculating Spearman's rank correlation coefficient (Table 2). Multiple logistic regression analysis (Tables 3 and 4) extracted the ratio of grip strength to body weight and TUG time as variables influencing the presence/absence of AADL (at $\mathrm{p}<0.01$ in the $\chi^{2}$ suitable model test). With age and gender as confounding variables, the odds ratios of grip strength to body weight and TUG time were 1.11 (95\% confidence interval: $1.00-1.23)$ and 0.58 $(0.37-0.90)$, respectively, and both showed a significance probability of $\mathrm{p}<0.05$. This model was confirmed to fit, at $\mathrm{p}=0.10$, in the Hosmer-Lemeshow test. The hit rate of discrimination between predicted and actual values was $87.2 \%$.

Using the ROC curve with the presence/absence of AADL as a dependent variable, the following values were obtained for the ratio of grip strength to body weight: AUC, 0.78 ( $\mathrm{p}<0.01$ ); $95 \%$ confidence interval, $0.64-0.92$; cutoff, $44.9 \%$; sensitivity, 0.689; and false positive rate, 0.083 . Similarly, those for the TUG time were as follows: AUC, 0.77 ( $<<0.01)$; $95 \%$ confidence interval, 0.64-0.91; cutoff, 8.25 seconds; sensitivity, 0.581 ; and false positive rate, 0.083 (Table 5).

Table 1. Comparison of basic attributes, PGC Morale Scale Scores, and physical function between participants with and without AADL

\begin{tabular}{|c|c|c|c|c|c|c|c|}
\hline & \multicolumn{3}{|c|}{ With AADL $(n=74)$} & \multicolumn{3}{|c|}{ Without AADL $(n=12)$} & \multirow[b]{2}{*}{ p-value } \\
\hline & Mean \pm SD & $\begin{array}{l}\text { Minimum } \\
\text { value }\end{array}$ & $\begin{array}{l}\text { Maximum } \\
\text { value }\end{array}$ & Mean \pm SD & $\begin{array}{l}\text { Minimum } \\
\text { value }\end{array}$ & $\begin{array}{l}\text { Maximum } \\
\text { value }\end{array}$ & \\
\hline Age (years) $\left.{ }^{a}\right)$ & $76.7 \pm 5.7$ & 65 & 88 & $77.2 \pm 2.8$ & 73 & 81 & \\
\hline Height $(\mathrm{cm})^{\mathrm{a})}$ & $152.6 \pm 7.4$ & 138.0 & 174.4 & $148.5 \pm 8.2$ & 139.7 & 164.0 & \\
\hline Body weight $(\mathrm{kg})$ & $56.5 \pm 9.9$ & 38.4 & 95.0 & $54.7 \pm 8.4$ & 46.4 & 73.0 & \\
\hline $\begin{array}{l}\text { Ratio of grip strength to body } \\
\text { weight (\%) }\end{array}$ & $48.6 \pm 8.7$ & 24.6 & 66.6 & $40.5 \pm 7.3$ & 29.6 & 57.8 & $* *$ \\
\hline $\begin{array}{l}\text { Ratio of knee extensor muscle } \\
\text { strength to body weight (\%) }\end{array}$ & $44.3 \pm 10.0$ & 20.7 & 69.2 & $37.3 \pm 13.1$ & 17.1 & 56.5 & \\
\hline $\mathrm{FR}(\mathrm{cm})$ & $31.6 \pm 5.1$ & 19.0 & 41.5 & $28.2 \pm 5.6$ & 20.5 & 42.0 & $*$ \\
\hline OLS time (seconds) & $31.9 \pm 34.1$ & 1.4 & 120.0 & $8.4 \pm 6.4$ & 1.3 & 23.0 & $* *$ \\
\hline TUG time (seconds) & $8.15 \pm 1.57$ & 4.90 & 12.1 & $10.68 \pm 3.30$ & 7.00 & 17.50 & $* *$ \\
\hline $\begin{array}{l}\text { PGC Morale Scale score } \\
\text { (points) })^{b}\end{array}$ & 14 & 4 & 17 & 12 & 6 & 16 & \\
\hline Agitation & 3 & 0 & 3 & 2 & 1 & 3 & \\
\hline Attitude toward own aging & 4 & 1 & 5 & 2 & 0 & 5 & $* *$ \\
\hline Lonely dissatisfaction & 6 & 2 & 7 & 6 & 2 & 7 & \\
\hline
\end{tabular}

Mann-Whitney U test

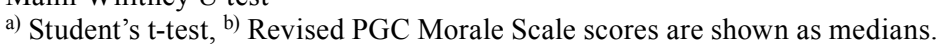

${ }^{*} \mathrm{p}<0.05 ;{ }^{* *} \mathrm{p}<0.01$

Table 2. Items showing significant values in univariate analysis and Spearman's rank correlation coefficient for age

\begin{tabular}{lcccccc}
\hline Measurement items & 1 & 2 & 3 & 4 & 5 & 6 \\
\hline 1. Ratio of grip strength to body weight & - & $0.354^{* *}$ & $0.312^{* *}$ & $-0.235^{*}$ & 0.206 & 0.006 \\
2. FR & - & - & $0.340^{* *}$ & $-0.438^{* *}$ & $0.241^{*}$ & $-0.263^{*}$ \\
3. OLS time & - & - & - & $-0.453^{* *}$ & $0.239^{*}$ & $-0.412^{* *}$ \\
4. TUG time & - & - & - & - & $-0.349^{* *}$ & $0.466^{* *}$ \\
5. PGC Morale Scale score (attitude toward own aging) & - & - & - & - & - & -0.096 \\
6. Age & - & - & - & - & - & - \\
\hline${ }^{*} \mathrm{p}<0.05 ;{ }^{* *} \mathrm{p}<0.01$ & & & & & &
\end{tabular}




\section{DISCUSSION}

This study examined 86 elderly residents participating in health promotion classes in their communities and who were able to independently transport themselves and appropriately communicate. The subjects may be regarded as vigorous elderly community residents due to their active attitudes toward community-based and health-promoting activities and ability to independently access a venue.

Among the participants, $74(86.0 \%)$ and $12(14.0 \%)$ were classified as those with and without AADL, respectively. The 5 most frequent types of AADL accounted for $65 \%$ of all AADL, indicating that the proportion of elderly community residents with AADL was high but that variation in activity lacked.

Comparison of the study items between subjects with and without AADL demonstrated that there were significant differences in the score for the PGC Morale Scale attitude toward own aging sub-scale, ratio of grip strength to body weight, FR, and OLS and TUG times. Such differences were not observed in knee extensor muscle strength. The score for attitude toward own aging and OLS and TUG times, as well as the ratio of grip strength to body weight, were more favorable among subjects with AADL.

While there were no significant differences in PGC Morale Scale score, that for the attitude toward own aging sub-scale markedly varied between subjects with and without AADL. When comparing medians, subjects without AADL showed lower values, confirming a difference between the two groups and suggesting that morale may influence the presence/absence of AADL, although the difference was not statistically significant.

Grip strength, a comprehensive muscle strength index, has been reported to be associated with knee extensor muscle strength $^{11)}$. It is also regarded as useful in predicting walking velocity and the ability to stand ${ }^{12}$. The TUG test, the reliability and validity of which have been confirmed, is also usable for fall risk assessment ${ }^{16)}$, and the time needed to complete the TUG task has been reported to be closely associated with lower-limb muscle strength, balance, walking ability, and daily living

Table 3. Results of multiple logistic regression analysis with the presence/absence of AADL as a dependent variable

\begin{tabular}{|c|c|c|c|c|c|c|c|c|}
\hline & \multirow{2}{*}{ B } & \multirow{2}{*}{$\pm \mathrm{SD}$} & \multirow{2}{*}{ Wald } & \multirow{2}{*}{$\begin{array}{l}\text { Degree of } \\
\text { freedom }\end{array}$} & \multirow{2}{*}{ p-value } & \multirow{2}{*}{ Odds ratio } & \multicolumn{2}{|c|}{$95 \%$ confidence interval } \\
\hline & & & & & & & Lower limit & Upper limit \\
\hline Ratio of grip strength to body weight (\%) & 0.10 & 0.05 & 4.50 & 1 & * & 1.10 & 1.01 & 1.21 \\
\hline TUG time (seconds) $)^{\mathrm{b})}$ & -0.46 & 0.19 & 5.71 & 1 & * & 0.63 & 0.43 & 0.92 \\
\hline Constant value & 1.68 & 2.63 & 0.41 & 1 & & 5.38 & & \\
\hline
\end{tabular}

$\chi^{2}$ suitable model test, $\mathrm{p}<0.01$; Hosmer-Lemeshow test, $\mathrm{p}=0.07$; hit rate of discrimination, $88.1 \%$

a) Higher values indicate positive results, ${ }^{\text {b) }}$ Lower values indicate positive results.

${ }^{*} \mathrm{p}<0.05 ;{ }^{* *} \mathrm{p}<0.01$

Table 4. Results of multiple logistic regression analysis with the presence/absence of AADL as a dependent variable (and age and gender as a confounding variables)

\begin{tabular}{|c|c|c|c|c|c|c|c|c|}
\hline & \multirow{2}{*}{ B } & \multirow{2}{*}{$\pm \mathrm{SD}$} & \multirow{2}{*}{ Wald } & \multirow{2}{*}{$\begin{array}{l}\text { Degree of } \\
\text { freedom }\end{array}$} & \multirow{2}{*}{ p-value } & \multirow{2}{*}{ Odds ratio } & \multicolumn{2}{|c|}{$95 \%$ confidence interval } \\
\hline & & & & & & & Lower limit & Upper limit \\
\hline Ratio of grip strength to body weight (\%) & 0.10 & 0.05 & 4.07 & 1 & * & 1.11 & 1.00 & 1.23 \\
\hline TUG time (seconds) $)^{b)}$ & -0.55 & 0.23 & 5.98 & 1 & * & 0.58 & 0.37 & 0.90 \\
\hline Age & 0.05 & 0.08 & 0.39 & 1 & & 1.05 & 0.90 & 1.23 \\
\hline Gender & 0.19 & 1.01 & 0.04 & 1 & & 1.21 & 0.17 & 8.77 \\
\hline Constant value & -1.30 & 5.81 & 0.05 & 1 & & 0.27 & & \\
\hline
\end{tabular}

$\chi^{2}$ suitable model test, $\mathrm{p}<0.01$; Hosmer-Lemeshow test, $\mathrm{p}=0.10$; hit rate of discrimination, $87.2 \%$

a) Higher values indicate positive results, ${ }^{\text {b) }}$ Lower values indicate positive results.

${ }^{*} \mathrm{p}<0.05 ;{ }^{* *} \mathrm{p}<0.01$

Table 5. Area under the ROC curve and cutoff

\begin{tabular}{lccccccc}
\hline & AUC & \pm SD & $95 \%$ CI & p-value & Cutoff & Sensitivity & False positive rate \\
\hline Ratio of grip strength to body weight (\%) & 0.78 & 0.07 & $0.64-0.92$ & ${ }^{* *}$ & 44.9 & 0.689 & 0.083 \\
TUG time (seconds) & 0.77 & 0.06 & $0.64-0.91$ & ${ }^{* *}$ & 8.25 & 0.581 & 0.083 \\
\hline
\end{tabular}

${ }^{*} \mathrm{p}<0.05 ;{ }^{* *} \mathrm{p}<0.01$ 
function ${ }^{10,14,15)}$. However, in the present study, significant differences between subjects with and without AADL were observed in grip strength, FR, and OLS and TUG times, and not in knee extensor muscle strength. Based on this, the presence/ absence of AADL may have a closer relation with grip strength, FR, and OLS and TUG times than with knee extensor muscle strength. Because elderly community residents with AADL are likely to perform physical activities frequently and go out, factors other than the musculoskeletal system, such as the sensory system and prediction mechanisms, may have improved the participants' balance and walking abilities, leading to less close association of knee extensor muscle strength in this study.

In our univariate analysis, the PGC Morale Scale attitude toward own aging sub-scale, ratio of grip strength to body weight, FR, and OLS and TUG times were identified as significant items. Our multiple logistic regression analysis, performed with these items and the presence/absence of AADL as independent and dependent variables, respectively, identified the ratio of grip strength to body weight and TUG time as variables influencing the presence/absence of AADL, confirming that the subjects with AADL had higher grip strength and physical function levels represented by TUG times. When entering age and gender as a confounding variable, the probability of performing AADL increased by 1.11 per $1 \%$ rise in the ratio of grip strength to body weight. Similarly, the probability increased by 1.72 as the TUG time decreased in 1-second. The cutoff was $44.9 \%$ for the ratio of grip strength to body weight and 8.25 seconds for the TUG time. In a previous study that reported about the relationship between activities of daily living (ADL) independence and grip strength in older adults (142 men and 205 women, mean age $74.8 \pm 8.8$ years), maximum strength was shown to be useful ${ }^{17)}$. The importance of grip strength was indicated not only for ADL but also for AADL. The TUG time is a useful index to identify elderly individuals at an increased risk of falls, with a cutoff of 13.5 seconds $^{13)}$. In the present study, the cutoff TUG time in relation to the presence/absence of AADL was 8.25 seconds; because the subjects were elderly community residents participating in health promotion classes and able to independently transport themselves, their fall risk levels were likely low, supporting the validity of such a cutoff. Considering that a decline in walking ability may lead to a limited range of activity and decreased ADL and QOL ${ }^{16,18)}$, as well as increased care facility use and death ${ }^{19,20)}$, it may be important to focus on the improvement of walking ability to promote elderly health.

Because this was a cross-sectional investigation, a limitation of this study, we were able to understand the relations of the presence/absence of AADL with morale and physical function. However, a longitudinal study regarding whether morale and physical function affect maintenance of AADL is necessary in the future. It may also be necessary to include more diverse groups, in addition to health promotion class participants, because the subjects of the present study were limited to elderly community residents showing active attitudes toward community-based and health-promoting activities and who were able to independently access a venue and perform ADL.

Furthermore, to encourage the elderly to perform AADL, psychological approaches, other than good morale and physical function, may also be essential. The elderly's sense of enjoying activities has been reported to be associated with 3 factors: cognition and tasks, self-assertiveness social relations, and emotions ${ }^{21)}$. Based on this, stimulation using these factors may be key to development of abilities to perform AADL.

Although this study examined elderly community residents who showed active attitudes toward community-based and health-promoting activities and were able to independently access a venue and perform ADL, their physical function, represented by grip strength and TUG time, differed depending on the presence/absence of AADL. In line with this, to develop abilities to perform AADL, it may be necessary to examine elderly individuals from viewpoints other than ADL independence; in other words, their grip strength and TUG times should be examined according to level of AADL.

\section{REFERENCES}

1) Reuben DB, Laliberte L, Hiris J, et al.: A hierarchical exercise scale to measure function at the Advanced Activities of Daily Living (AADL) level. J Am Geriatr Soc, 1990, 38: 855-861. [Medline] [CrossRef]

2) Dias EG, Andrade FB, Duarte YA, et al.: Advanced activities of daily living and incidence of cognitive decline in the elderly: the SABE Study. Cad Saude Publica, 2015, 31: 1623-1635. [Medline] [CrossRef]

3) De Vriendt P, Gorus E, Cornelis E, et al.: The process of decline in advanced activities of daily living: a qualitative explorative study in mild cognitive impairment. Int Psychogeriatr, 2012, 24: 974-986. [Medline] [CrossRef]

4) De Vriendt $\mathrm{P}$, Gorus E, Cornelis E, et al.: The advanced activities of daily living: a tool allowing the evaluation of subtle functional decline in mild cognitive impairment. J Nutr Health Aging, 2013, 17: 64-71. [Medline] [CrossRef]

5) Blakeslee TR, Grossarth-Maticek R: Feelings of pleasure and well-being as predictors of health status 21 years later. Retrieved from http://www.attitudefactor.com/PWItecharticle.htm.

6) Michael YL, Berkman LF, Colditz GA, et al.: Living arrangements, social integration, and change in functional health status. Am J Epidemiol, 2001, 153: 123-131. [Medline] [CrossRef]

7) Lawton MP: The Philadelphia Geriatric Center Morale Scale: a revision. J Gerontol, 1975, 30: 85-89. [Medline] [CrossRef] 
8) Ikezoe T, Asakawa Y, Tsutou A: The Relationship between quadriceps strength and balance to fall of elderly admitted to a nursing home. J Phys Ther Sci, 2003, 15: 75-79. [CrossRef]

9) Duncan PW, Weiner DK, Chandler J, et al.: Functional reach: a new clinical measure of balance. J Gerontol, 1990, 45: M192-M197. [Medline] [CrossRef]

10) Podsiadlo D, Richardson S: The timed "Up \& Go": a test of basic functional mobility for frail elderly persons. J Am Geriatr Soc, 1991, 39: 142-148. [Medline] [CrossRef]

11) Rantanen T, Era P, Kauppinen M, et al.: Maximal isometric muscle strength and socio-economic status, health and physical activity in 75-year-old persons. J Aging Phys Act, 1994, 2: 206-220.

12) Rantanen T, Guralnik JM, Foley D, et al.: Midlife hand grip strength as a predictor of old age disability. JAMA, 1999, 281: 558-560. [Medline] [CrossRef]

13) Shumway-Cook A, Brauer S, Woollacott M: Predicting the probability for falls in community-dwelling older adults using the Timed Up \& Go Test. Phys Ther, 2000, 80: 896-903. [Medline]

14) Bischoff HA, Conzelmann M, Lindemann D, et al.: Self-reported exercise before age 40: influence on quantitative skeletal ultrasound and fall risk in the elderly. Arch Phys Med Rehabil, 2001, 82: 801-806. [Medline] [CrossRef]

15) Samson MM, Meeuwsen IB, Crowe A, et al.: Relationships between physical performance measures, age, height and body weight in healthy adults. Age Ageing, 2000, 29: 235-242. [Medline] [CrossRef]

16) Furuna T, Nagasaki H, Nishizawa S, et al.: Longitudinal change in the physical performance of older adults in the community. J Jpn Phys Ther Assoc, 1998, 1: 1-5. [Medline] [CrossRef]

17) Matsui Y, Fujita R, Harada A, et al.: Association of grip strength and related indices with independence of activities of daily living in older adults, investigated by a newly-developed grip strength measuring device. Geriatr Gerontol Int, 2014, 14: 77-86. [Medline] [CrossRef]

18) Guralnik JM, Ferrucci L, Simonsick EM, et al.: Lower-extremity function in persons over the age of 70 years as a predictor of subsequent disability. N Engl J Med, 1995, 332: 556-561. [Medline] [CrossRef]

19) Guralnik JM, Simonsick EM, Ferrucci L, et al.: A short physical performance battery assessing lower extremity function: association with self-reported disability and prediction of mortality and nursing home admission. J Gerontol, 1994, 49: M85-M94. [Medline] [CrossRef]

20) Gibbs J, Hughes S, Dunlop D, et al.: Predictors of change in walking velocity in older adults. J Am Geriatr Soc, 1996, 44: 126-132. [Medline] [CrossRef]

21) Yajima M, Asakawa Y, Yamaguchi H: Contents and construct of subjective enjoyment of community-dwelling elderly people performing physical activities. J Phys Ther Sci, 2013, 25: 207-209. [CrossRef] 